\title{
El Aleph de Roger Caillois en Gallimard o de cómo salir del laberinto
}

\section{Introducción}

La difusión de la obra de Borges en Francia es un caso paradigmático para analizar los procesos de traducción en el marco de la literatura mundial. En este artículo nos proponemos estudiar el contexto de publicación de los volúmenes Labyrinthes y El Aleph en francés, a partir de la hipótesis de que la operación de traducción y montaje realizada por Caillois modifica la obra de Borges y crea un corpus nuevo, a través del cual su recepción adquiere rasgos específicos: se construye en Francia, y a través de Francia, una obra que difiere de la que encontramos en español.

Fictions en la traducción de Paul Verdevoye y Néstor Ibarra inaugura la colección La Cruz del Sur en 1951, dirigida por Roger Caillois en Gallimard, así como la difusión de la obra de Borges en forma de volumen en lengua francesa; en 1953, el mismo Caillois traduce y publica un conjunto de cuentos de Borges, Labyrinthes. Si el primero retoma el contenido de la versión española de Ficciones según su edición de 1944, el segundo es una construcción realizada por Caillois, y contiene relatos provenientes de El Aleph (1949): "L'immortel", "Histoire du guerrier et de la captive", "L'écriture du Dieu”, "La quête d'Averroès". Labyrinthes tuvo un éxito considerable y fue traducido a varios idiomas (al inglés y al alemán en 1961), por lo que se lo considera una exitosa operación crítica de traducción. Si partimos del principio borgeano que una literatura difiere de otra menos por sus textos que por el modo en que es leída, tal como lo expresa en "Nota sobre (hacia) Bernard Shaw" (192), podemos decir que Labyrinthes pertenece a la literatura francesa y no a la argentina, porque este libro va a adquirir rápidamente el valor de obra autónoma. Recordemos también que Fictions y Labyrinthes son objetos de aspecto diferente: Labyrinthes es un pequeño volumen lujoso, con una tapa particularmente trabajada, y una disposición del texto elegante y espaciada (en-16), mientras Fictions toma la forma de la colección La Croix du Sud, más económica, destinada a una difusión vasta. Una tercera etapa

1 "L’immortel" había sido publicado en La Nouvelle Revue Française, el 1ero de septiembre de 1953.

Annick Louis, CRAL (EHESS-CNRS), Universidad de Reims-CRIMEL

¿ Open Access. (C) 2020 Annick Louis, published by De Gruyter. (cc) BY-NC-ND This work is licensed under a Creative Commons Attribution-NonCommercial-NoDerivatives 4.0 International License.

https://doi.org/10.1515/9783110673678-008 
en la edición francesa de la literatura de Borges es la publicación por Caillois de otro conjunto de textos de Borges en enero de 1957, bajo el título de "Trois labyrinthes", en la revista Preuves ${ }^{2}$, número 71 (38-43), que comprende "La demeure d’Astérion” (proveniente también de El Aleph), "Les précurseurs de Kafka”, "La création et P. H. Gosse” (Otras inquisiciones, 1952) ${ }^{3}$.

El "desmantelamiento" al que Caillois somete el volumen El Aleph ha intrigado a lectores e investigadores. Entre los argumentos que se han propuesto para justificarlo se encuentran el supuesto desinterés de los lectores franceses por la forma cuento; el eclecticismo de la producción de Borges; el intento de aprovechar un cambio en el lectorado, que se produce a comienzos de los años 1950 en Francia, cuando el interés por la literatura testimonial y realista comienza a ceder en favor de la de imaginación. Sin embargo, comprender las razones que llevaron a Caillois a realizar este montaje en vez de publicar El Aleph resulta menos interesante que constatar los efectos del volumen en la cultura francesa e internacional. Por un lado, el libro se volvió esencial al conocimiento de Borges, proponiendo el laberinto como un prisma interpretativo a través del cual será percibida y comprendida su obra. Su otro efecto inesperado fue atrasar la publicación de El Aleph hasta $1967^{4}$, y posicionar esta obra de Borges igualmente bajo el signo del laberinto, puesto que Caillois retoma en este volumen su prefacio a Labyrinthes, con ligeras modificaciones. Recordemos también que cuando se publica la versión francesa, ha habido ya tres ediciones de $E l$ Aleph: la de 1949 en la editorial Losada, la primera; la de 1952 en la misma editorial, en la cual Borges agrega los relatos: “Abenjacán el bojarí, muerto en su laberinto”, "Los dos reyes y los dos laberintos”, "La espera”, "El hombre en el umbral” (y un postfacio); la de Emecé de 1957, en el marco de las primeras Obras completas.

Fuera de los que ya figuraban en Labyrinthes, en L'Aleph, Caillois elige traducir "La casa de Asterión”, “Abenjacán el Bojarí, muerto en su laberinto” e "Historia de los dos reyes y los dos laberintos”, todos cuentos en los que encontramos el

2 Preuves (1951-1969) [1era serie]. Revue mensuelle littéraire et politique. Cahiers mensuels du Congrès pour la liberté de la culture. Sous les auspices du Congrès pour la liberté de la culture, Paris. Dirigida por François Bondy. Se publicaron 220 números.

3 Como lo señala Molloy, el caso de Borges es paradójico porque, contrariamente a otros escritores hispanoamericanos, no hizo nada para ser descubierto y difundido en Francia, y porque sus relaciones con la cultura francesa no son privilegiadas (195).

4 Caillois pide a Victoria Ocampo en una carta cuya datación no es certera que le envíe un ejemplar de El Aleph, Carta de Caillois a Victoria Ocampo, fechada tentativamente el 19 janvier [1953] (Caillois y Ocampo 332). Si la fecha fuera correcta, esto significaría que Caillois no empieza a interesarse en El Aleph sino después de la publicación de Fictions en francés y en el momento en que monta Labyrinthes, lo cual resulta algo sorprendente. 
tema del laberinto (los demás fueron traducidos por René L.-F. Durand). Entre la publicación de Labyrinthes y la de El Aleph se editan varios libros de Borges en francés, se difunde vastamente su obra y se asienta su fama en Francia y en el mundo: Enquêtes 1937-1952 en "La Croix du Sud”, Gallimard en 1957; Histoire de l'infamie. Histoire de l'éternité en 1958; La Bibliothèque de Babel en 1963; L'Auteur et autres textes en "La Croix du Sud", Gallimard en 1965; Manuel de zoologie fantastique en 1965; Discussion también en "La Croix du Sud” en 1966; Essai sur les anciennes littératures germaniques en 1966.

En este trabajo queremos proponer una reflexión sobre las causas y los efectos de la operación mediante la cual, como se ha dicho a menudo, Caillois reescribe a Borges en sus ediciones y traducciones, otorgando una identidad específica a su obra y dejando de lado numerosas facetas de la literatura de Borges, que el público francés conocerá recién gracias a los dos tomos de las Obras completas de La Pléiade publicados en 1993 y 1999. Nos concentramos aquí en la relación entre la fabricación del tema del laberinto como eje de la obra de Borges y la publicación de L'Aleph.

\section{Los laberintos de Roger Caillois}

Si la verdadera difusión de la literatura de Borges en Francia comienza con Fictions $^{5}$, antes de la Segunda Guerra Mundial, es decir, en la época en que Borges es esencialmente poeta y ensayista, y hace sus primeros pasos como narrador, solamente dos textos habían sido publicados gracias a la intervención de Ricardo Güiraldes, Valéry Larbaud y Néstor Ibarra: "Paul Groussac" en La Revue Argentine; "L'approche du caché” en traducción de Néstor Ibarra en Mesures en $1939^{6}$. Durante la guerra, dos relatos se editaron en Argentina en francés, en la revista fundada y dirigida por Roger Caillois, Lettres françaises: “Assyriennes”, "La loterie de Babylone” y "La bibliothèque de Babel”, traducidos y presentados por Néstor Ibarra; luego del retorno de Caillois, varios cuentos aparecen en diferentes revistas, gracias a su iniciativa, lo cual traduce la intención de preparar el terreno para la publicación de los volúmenes: “Les Assyriennes: La loterie

5 Respecto de Caillois, su regreso a Francia y la colección La Croix du Sud, ver Felgine; Río de la Plata 1992.

6 Recordemos la evaluación negativa de Caillois al respecto en una carta dirigida a Paulhan del 26 de julio de 1939, donde, a propósito de "El acercamiento a Almotasim" afirma que Borges no se expresa seriamente (Caillois y Paulhan 118). 
de Babylone; Les ruines circulaires", traducción de Paul Verdevoye, en Confluences en 1946; "Fictions", traducción del mismo Paul Verdevoye en La Licorne en 1947; "Histoire du guerrier et de la captive”, traducción de Roger Caillois, en Cahiers de la Pléiade, en $1949^{7}$. Si el proyecto de crear una colección destinada a difundir la literatura hispano-americana surge rápidamente una vez Caillois está de regreso en Francia (Caillois y Ocampo 226), como hemos podido demostrarlo, no existe una continuidad entre sus proyectos desarrollados en Argentina, y la creación de esta colección, puesto que en la revista Lettres françaises, no encontramos una política de difusión de literaturas traducidas, aunque sí se presenta como el refugio de "la otra Francia”, exilada y censurada bajo la ocupación, identificada con la alta cultura y con valores humanistas (Louis, "Étoiles”, “La traduction”).

La operación cultural realizada por Caillois debe en parte su éxito a los diferentes niveles en que interviene: sus ediciones y traducciones se acompañan de un aparato crítico, una serie de prefacios y ensayos, donde sistematiza su lectura, presentando al laberinto como un tema y como una suerte de "inspiración” común de la obra de Borges. Así, en su "Avertissement” en Labyrinthes afirma: "Le thème du labyrinthe n'y est pas toujours explicitement évoqué. En revanche, plusieurs contes du même recueil, que pourtant je n'ai pas cru devoir retenir, se passent dans des labyrinthes mais ceux-ci ne sont que des décors, c'est-à-dire des labyrinthes réels, où s'égare cette fois le corps, non la pensée du héros" (Labyrinthes 9$)^{8}$. El laberinto se presenta, entonces, como una figura mental, no necesariamente geográfica, y se erige en matriz que permite explicar el funcionamiento de la obra de Borges, integrando géneros y diferentes períodos de su producción; porque los cambios de orientación y de referencias literarias, los desplazamientos genéricos pueden verse como una dificultad a la hora de presentar a Borges, autor cuyo recorrido podía parecer incoherente o, al menos, difícil de comprender. La noción de laberinto como representación del universo, por otro lado, permite la apertura hacia una visión filosófica, metafísica, de la obra de Borges, que se convirtió rápidamente en una suerte de doxa interpretativa: "Le labyrinthe fournit ainsi le constant et naturel symbole de l'intuition fondamentale qui fait l'unité des quatre apologues contenus dans ce petit livre et de nombreux autres textes - prose ou vers- de Jorge Luis Borges”

\footnotetext{
7 "Histoire du guerrier et de la captive", había sido publicado en Cahiers de la Pléiade, en el otoño de 1949, pp. 159-164.

8 "El tema del laberinto no es siempre evocado explícitamente. En cambio, varios cuentos del volumen, que sin embargo no creí bueno retener, se desarrollan en laberintos, pero éstos no son más que un decorado, es decir laberintos reales, donde esta vez se pierde el cuerpo no el pensamiento del héroe".
} 
(Labyrinthes 10; L'Aleph 10) ${ }^{9}$. En la breve introducción que acompaña la publicación de Preuves en 1957, Caillois cita su propio prólogo de Labyrinthes (10-11), afirmando la figura del laberinto como una simetría abstracta que permite una síntesis de lo antinómico (en acuerdo con su visión de América Latina $)^{10}$, y agrega la idea de que esta figura rige también su producción crítica porque, en ella, "Borges apparaît également obsédé par les rapports du fini et de l'infini"11 (38).

Caillois explicará su posición y sus elecciones en el ensayo del número de L'Herne dedicado a Borges (1964), "Les thèmes fondamentaux de Jorge Luis Borges”, donde afirma que el principal "thème-clé” (tema-clave) de su obra es el tiempo circular, y que este "en entraîne deux autres qui en représentent comme les projections dans les domaines de l'espace et de la causalité : celui du labyrinthe et celui de la création recurrente" (Labyrinthes 211) ${ }^{12}$. A partir de ahí, da una explicación de lo que llama "l'arrière-plan métaphysique de l'univers de Jorge Luis Borges” (Labyrinthes 214) ${ }^{13}$ :

Borges se trouva contraint de faire correspondre à la durée circulaire une étendue également circulaire. Ce fut le labyrinthe, lequel acquit chez lui une valeur obsédante. Réel ou métaphorique, matériel, moral ou intellectuel, il procure le lieu privilégié de nombreux récits, non seulement de ceux que j'ai réunis et traduits sous ce titre même de Labyrinthes, mais encore de La demeure d'Astérion, d'Abenhakan el Bokhari mort dans son labyrinthe, et d'autres. La loterie de Babylone, La bibliothèque de Babel, sont, à leur manière, des labyrinthes, et naturellement aussi Le jardin aux sentiers qui bifurquent. (Labyrinthes 214) ${ }^{14}$

Notemos la curiosa expresión "se encontró obligado" que atribuye una intención autorial a Borges que en verdad responde a la interpretación del crítico, y

9 "El laberinto provee así el símbolo constante y natural de la intuición fundamental que hace la unidad de los cuatro apólogos contenidos en ese pequeño libro y numerosos otros textos -en prosa o en verso- de Jorge Luis Borges".

10 Tal como lo afirma en su "Poètes d'Amérique. Note".

11 "Borges aparece también obsesionado por las relaciones de lo finito y lo infinito".

12 "arrastra dos otros que representan como las proyecciones en los dominios del espacio y de la causalidad: el del laberinto y el de la creación recurrente".

13 "el trasfondo metafísico del universo de Jorge Luis Borges".

14 "Borges se encontró entonces en la obligación de hacer corresponder a la duración circular una extensión también circular. Fue el laberinto, que adquirió en él un valor obsesivo. Real o metafórico, material, moral o intelectual, procura el espacio privilegiado de numerosos relatos, no solamente de los que he reunido y traducido bajo este título mismo de Labyrinthes, sino también La casa de Asterión, Abenjacán el bojarí muerto en su laberinto, y otros. La lotería en Babilonia, La biblioteca de Babel son, a su manera, laberintos y, naturalmente también El jardín de senderos que se bifurcan”. 
no a la lógica de la obra literaria. Al final de este ensayo, Caillois vincula la obra de Borges con la de otros autores (Jules Vernes, Arnold Toynbee, SaintJohn Perse) para afirmar el lugar de Borges en el Panteón europeo, considerado universal, puesto que estos autores "n'acceptent pour absolu aucun centre de références particulier, ni local, ni temporel” y "se veulent bénéficiaires de la totalité du monde, héritiers d'un humanisme universal” (Labyrinthes 217) ${ }^{15}$. El objetivo de la operación es, en parte, desarraigar a Borges de su propio contexto, así como de toda forma de exotismo y de localismo a partir de los cuales se perciben a menudo las literaturas extranjeras en Europa; y también inscribir a Borges en un canon de la literatura occidental, lo cual solamente puede hacerse, según Caillois, a partir de un intemporal, postulando la existencia de temas tradicionales de la cultura occidental como universales. Esta visión de la obra de Borges permite también explicar por qué Caillois adopta la presentación de Borges hecha por Ibarra en Lettres françaises en su edición de Fictions, gesto que ha desconcertado a la crítica latinoamericana (Molloy 206).

En L'Aleph, Caillois retoma el prefacio de Labyrinthes, completándolo con una justificación de sus elecciones, mientras recuerda sus diferentes compilaciones; dos frases nuevas son particularmente llamativas. La que encabeza el ensayo: "La traduction du recueil El Aleph a subi de nombreux et imprévisibles retards" (El Aleph 7) ${ }^{16}$; y la última: “Aujourd'hui que la traduction des dix autres contes du recueil est menée à bien par M. René L.-F. Durand, les récits que j'avais d'abord publiés à part reprennent la place qu'ils occupaient dans le recueil original et Labyrinthes disparaît, afin que la traduction française de l'ouvrage de J. L. Borges ne se trouve [sic] par répartie en deux volumes inégaux" (El Aleph 11) ${ }^{17}$. Como vemos, Caillois invierte aquí la relación causa-efecto, puesto que presenta sus propias compilaciones como una consecuencia de la falta de traducción de El Aleph, subrayando su origen. En cuanto a la frase final, notamos la idea de la "desaparición” del volumen Labyrinthes, así como la de dos volúmenes "desiguales" (o desparejos) en caso de que se conservara esa primera edición. Es evidente que más de diez años después, la exitosa recepción de Borges impone la publicación del volumen en su totalidad, pero el

15 "no aceptan como absoluto ningún centro de referencias particular, ni local, ni temporal"; "se vuelven beneficiarios de la totalidad del mundo, herederos de un humanismo universal".

16 "La traducción del volumen El Aleph sufrió numerosos e imprevistos retrasos".

17 "Hoy, cuando la traducción de los otros diez cuentos del volumen ha sido realizada por René L.-F. Durand, los relatos que había publicado primero aparte retoman el lugar que ocupaban en el volumen original y Labyrinthes desaparece, para evitar que la traducción francesa del libro de J. L. Borges esté repartida en dos volúmenes desiguales”. 
prefacio muestra claramente que Caillois defiende su lectura, y su interpretación de la obra del escritor, así como el montaje que había realizado.

\section{Historia del laberinto}

Para comprender la operación cultural realizada por Caillois es necesario reconstruir la presencia del laberinto en la obra de Borges en tanto tema, que permite percibir lo que su lectura oculta. Una tarea, sin embargo, de un alcance relativo, puesto que, como el mismo Caillois lo afirma, para él el laberinto es un tema, pero no en el sentido clásico, aunque es evidente que su concepción responde a la tradición de los estudios literarios franceses (Schaeffer). Sin embargo, la producción borgeana, en lengua original, en orden cronológico, en sus medios de publicación primeros, permite afirmar que el laberinto no tiene una presencia dominante, siquiera privilegiada, ni como espacio geográfico ni bajo la forma en que lo entiende Caillois: no aparece como un articulador privilegiado de sus ficciones, pero sí como como tema, como trama y como procedimiento; sus referencias y ocurrencias temáticas y explícitas son poco numerosas, y el lector no necesariamente les atribuye el valor que Caillois les otorga.

La aparición del laberinto se produce en los años 1935-1936; Borges lo asocia entonces a elementos muy distintos de aquellos que propone Caillois, y en particular a la trama policial; es en la nota bibliográfica sobre The Scandal of Father Brown de G. K. Chesterton (1935), "Los laberintos policiales y Chesterton”, donde el laberinto aparece de modo explícito; en ese texto Borges retoma parcialmente "Leyes de la narración policial", su primer ensayo sobre el género policial, donde no se menciona al laberinto. En el segundo artículo la idea aparece solamente en el título, pero al final del artículo se insinúa la orientación que toma: “¿Ha denunciado alguien la afinidad entre el Londres fantástico de Stevenson y el de Chesterton, entre los enlutados caballeros y jardines nocturnos del Suicide Club y los de la ahora quíntuple Saga del Padre Brown?" La ciudad en el cruce de lo fantástico y lo policial, como la literatura de Chesterton según Borges, la ciudad que se transforma en la encrucijada narrativa de un crimen, son elementos excluidos de la selección de Caillois.

La aparición siguiente del laberinto se da en 1936 y se encuentra en una nota publicada bajo el seudónimo de Daniel Haslam, "Laberintos”, en la revista Obra (revista del metro de Buenos Aires) ${ }^{18}$, nota bibliográfica sobre un libro

18 Obra. Revista Mensual Ilustrada. Borges fue secretario de redacción entre 1935 y 1936; en los números 3, 5 y 6 publica bajo el seudónimo de Daniel Haslam. 
imaginario: A General History of Labyrinths, Londres 1932, de Thomas Ingram, libro citado más tarde en “Tlön, Uqbar, Orbis Tertius”. En esta nota apócrifa, la reflexión gira alrededor de dos cuestiones esenciales, saber si el laberinto imita fenómenos naturales, y llegar a comprender si su efecto, perder a los hombres, resulta de una construcción arquitectural o si responde a otros factores (el alcohol, la distracción, la psicología). Cuando considera, a partir de Plinio, que es el autor de referencia del libro inexistente, el laberinto de Creta, anuncia lo que se volverá una interpretación constante del fenómeno: la identidad entre un lugar monstruoso y un habitante monstruoso, que encontramos en "La casa de Asterión”. Presenta luego su "Historia de los dos reyes y los dos laberintos", donde se pone en escena una oposición entre un laberinto construido por el hombre y uno natural (el desierto, obra de Dios en el texto).

Esta presentación traduce el desplazamiento entre el ensayo sobre el género policial y el relato, marcado por este género; al mismo tiempo se manifiesta una asociación entre la ciudad y el laberinto, mientras que este se desprende del espacio físico. El laberinto reaparece como se sabe en El jardín de senderos que se bifurcan (1941), y por tanto en Ficciones (1944), en textos como "La biblioteca de Babel”, y el mismo "Jardín de senderos que se bifurcan”; en El Aleph (1949), lo encontramos en "Los inmortales”, "La casa de Asterión”, y en la edición de 1952, se incorporan "Abenjacán el Bojarí, muerto en su laberinto" y el ya mencionado "Los dos reyes y los dos laberintos”. Varios de estos relatos combinan la trama policial con la ciudad, que se transforma en un laberinto, subrayando así la importancia del policial en la espacialización de la trama en Borges, elemento ajeno a la lectura de Caillois que otorga mayor importancia a la perspectiva filosófica del tema del laberinto, y privilegia textos que no ocurren en Buenos Aires (Louis, Borges).

Al transformar al laberinto en un tema, en la mejor tradición de los estudios literarios franceses, Caillois ignora deliberadamente la función del laberinto en Borges en tanto trama y procedimiento narrativo; inscribe así una impronta metafísica en los textos, que ignora otro componente de la escritura de Borges: el humor, que desaparece en sus traducciones. Al mismo tiempo el reenvío a un mundo urbano y porteño son ocultados, y los espacios, temas y personajes pertenecientes a la tradición occidental ensalzados. Los relatos agregados a la edición de El Aleph de 1952, permiten pensar que Borges despliega el tema del laberinto a partir de la recepción de Labyrinthes, en direcciones diferentes de las propuestas por Caillois, en un gesto que caracteriza su literatura, y que consiste en volver productiva la recepción de su obra, y explotar sus condiciones de recepción para producir literatura. 


\section{Quién habla a través de la lengua del traductor}

Como es sabido, Caillois va a Argentina a dictar una serie de conferencias, en julio de 1939, pero el advenimiento de la Segunda Guerra Mundial determina que se quede hasta 1945. Varios testimonios sugieren que no aprende español, puesto que se mueve en la comunidad de relaciones y amistades de Victoria Ocampo, donde prácticamente todo el mundo habla francés. Los datos de los que disponemos sugieren que cuando vuelve a Francia sigue sin dominar la lengua; incluso en 1946 cuando traduce a Gabriela Mistral, su conocimiento del idioma es relativo, como podemos deducirlo de sus traducciones y su postfacio ${ }^{19}$. Agreguemos que quien sí aprende rápidamente español es su primera esposa, Yvette Billod Caillois (1914-2008), que llega a Argentina en 1940, gracias también a la ayuda de Victoria, para casarse con Roger, luego de haber dado nacimiento a la hija de ambos en Francia; a su regreso, Yvette obtiene la agregación de español, y colabora con su marido en diferentes empresas intelectuales, como lo había hecho en Argentina. El aprendizaje de Caillois del español, por tanto, se realiza en la práctica misma de la traducción, primero traduciendo a Gabriela Mistral, luego a Borges, y más tarde a otros autores, como Cortázar y Octavio Paz; la falta de dominio del idioma representa sin duda un obstáculo técnico, pero a ello viene a sumarse la consciencia (o falta de) que el traductor tiene de sus propios límites. Agreguemos a esto una cuestión esencial para toda traducción literaria, Caillois ignora las tradiciones literarias hispanoamericanas, lo que vuelve imposible toda contextualización de la lengua: traduce como si no fuera necesario conocer la tradición literaria para realizar una traducción de calidad.

Gracias a su correspondencia y a sus escritos podemos intentar comprender la concepción de la lengua y de la tarea de la traducción de Caillois, estrechamente vinculadas a sus ideas sobre la literatura, que conviene resumir rápidamente; es necesario aclarar, sin embargo, que sus decisiones y actitudes resultan a menudo contradictorias, a pesar de su intensa reivindicación de la racionalidad. Como ha sido señalado, las posiciones de Caillois sobre la literatura estuvieron marcadas por su adhesión al surrealismo primero, por su toma de distancia respecto del movimiento en un segundo momento, y luego por su

19 Varios testimonios y su propia correspondencia permiten comprobarlo, como por ejemplo las declaraciones de Jean José Marchand (Felgine 211). Ver también el informe del embajador de Francia en Cuba así como la carta de protesta de un guatemalteco del 20 de marzo de 1946, dirigida al director del servicio de propaganda del Ministerio de Relaciones exteriores, a propósito de la conferencia que Caillois dio el 12 de marzo sobre Lautréamont (Felgine 291; fuente Ministerio de Relaciones Extranjeras, Relaciones culturales 1945-1947, dossier "Affaire Caillois”, Carta del 20 de marzo de 1947). 
ferviente animosidad hacia este ${ }^{20}$. Los años pasados en Buenos Aires también contribuyen a dar una nueva orientación a sus concepciones, que se expresan entonces en la revista Lettres françaises ${ }^{21}$; como para muchos exilados, la lengua materna funcionó para él como un refugio, lo cual modificó su concepción de la lengua, y de la literatura, y, probablemente, lo llevó a resistirse a aprender el español ${ }^{22}$. En cuanto a la literatura, si el joven Caillois había expresado su desconfianza hacia la poesía y la ficción, pronunciándose en favor del ensayo, en su "Manifeste pour une Littérature édifiante" (1944) define la política de la revista, a partir de una oposición entre lo que llama "literatura edificante" y "literatura recreativa" ("de divertissement"), donde lo edificante se sitúa en el estilo (2). Todo indica que esta oposición organiza todavía las concepciones de Caillois en los años 1950 y 1960, aunque sin duda la dimensión filosófica que otorga al laberinto desprende la literatura de Borges de lo meramente recreativo, conservando sin embargo su aspecto imaginativo. Podemos, por tanto, concluir que la importancia de Borges en la obra de Caillois viene en parte del hecho que le permite realizar una síntesis de su concepción que oponía hasta entonces dos tipos de literatura. La marca de la literatura edificante (una preferencia que compartía con Victoria Ocampo) impone una serie de elecciones en el momento de traducir. Agreguemos unas palabras acerca su concepción de la lengua, que se presenta como un medio, o un prisma: un modo de "expresión" de algo otro -la identidad cultural, por ejemplo-. La ficción y la poesía son, así, consideradas como instrumentos de conocimiento, como lo ha señalado ya Roger Bastide.

En las traducciones de Caillois otro aspecto de sus concepciones entra en juego, determinante en su producción ensayística global, que es uno de los elementos que organizaron su epistemología: la idea que existen estructuras comunes a la naturaleza y a las producciones de los hombres, artísticas en particular. Llamamos a este movimiento la "ausencia de arbitrariedad", expresión que designa una suerte de coherencia del mundo, que podemos pensar a partir del libro de Caillois Approches de la poésie, donde retoma su definición de la poesía como el lugar de la metáfora y de la analogía por excelencia, que

20 Así puede verse ya en una carta de Jules Supervielle a Jean Paulhan del 29 de junio de 1945. Archives Paulhan, citado por Felgine (271).

21 Veinte números fueron publicados en Buenos Aires entre julio de 1941 y junio de 1947; la revista estaba dirigida por Caillois, et financiada por Victoria Ocampo.

22 Existen testimonios que indican que Caillois era muy crítico respecto de la calidad de la lengua francesa hablada por las personas que encuentra en Argentina, e incluso que emprende una suerte de cruzada para salvar el francés en las regiones perdidas de América Latina. Ver Felgine (218-219). 
se integran en un movimiento más vasto: reflejan las posibilidades combinatorias de los fenómenos físicos y de los elementos (en el sentido científico del término), más allá del lenguaje y del hombre que lo habla. Se definiría de este modo una "razón poética" que se opone a la imagen poética de los surrealistas que, según Caillois, pone de relieve una relación gratuita y mística, que es lo que llama la "impostura de la poesía”. El objetivo entonces es acceder a imágenes que no sean fortuitas, ni arbitrarias, que no son inimaginables, y que no estén comprometidas con el azar y la gratuidad (Caillois, "Approches" 225-228). En otras palabras, no existiría una arbitrariedad ni del lenguaje ni de la literatura, sino un intento de aprehender estructuras existentes en el mundo, que se manifiestan bajo diferentes formas. No cabe duda de que esta concepción va a jugar un papel determinante no solamente en su interpretación de Borges, sino también en el modo en que lo editará, y lo traducirá -y más generalmente en su práctica de la traducción-. En efecto, se resignifica, así, la relación entre dos idiomas, puesto que el eje determinante se encuentra en la aptitud de cada uno de ellos a conectarse con esas estructuras no arbitrarias.

\section{Espacios de inscripción del traductor}

A partir de estas consideraciones, quisiera proponer algunas observaciones sobre las traducciones hechas por Caillois de los textos de El Aleph, que pueden encontrarse también en sus traducciones de otros autores como Cortázar u Octavio Paz (Taminiaux; Dulou). He aquí los tres tipos de fenómenos que hemos establecido hasta el momento, para señalar los modos en que la traducción de Caillois se aleja del texto en español, basándonos en una comparación de los textos de Borges traducidos por Caillois en El Aleph; por falta de espacio no podemos reproducir todos los ejemplos en su totalidad ${ }^{23}$. Esta propuesta parte del presupuesto que la traducción no es meramente un problema lingüístico, por lo que evito una categorización a partir de parámetros tradicionales -sintácticos, semánticos, léxicos-.

Una primera categoría la constituyen los contrasentidos, es decir aquello que solemos llamar "errores de traducción”, entre los cuales se encuentran los problemas debidos al descuido, o a un conocimiento defectuoso del español

23 En esta etapa del trabajo, comparo El Aleph de 1952 con L'Aleph de 1967, pero es evidente que sería interesante comparar todas las publicaciones de cada cuento. 
(de Argentina, en el caso de Borges) ${ }^{24}$. En general, suponemos que estos contrasentidos son involuntarios, y que no responden a una elección deliberada o meditada del traductor; pero en verdad hay dos casos dentro de esta categoría: a veces el traductor sabe que ignora el sentido de una palabra o expresión, o que no la conoce sino de modo aproximado; en otros casos, el traductor ignora que desconoce el significado de una palabra o de una expresión, y traduce de un modo que supone correcto. El caso de Caillois es particularmente interesante en este sentido, porque, a menudo, ignora su propia ignorancia. Como ejemplo de estos dos tipos de traducciones podemos citar los siguientes: entre los contrasentidos probablemente involuntarios, el comienzo de la frase "Hacia la medianoche, pisé, erizada de formas idolátricas en la arena amarilla, la negra sombra de sus muros" ("El inmortal", 1952: 12), en la cual Caillois traduce “Jusqu’à minuit. ..” (1967: 20) en vez de “Aux alentours de minuit”, lo que sugiere que ignora simplemente el matiz, o padece de distracción. Más interesante tal vez es el caso del contrasentido absoluto: "En tierra alguna es desconocido mi nombre..." (“Abenjacán el bojarí, muerto en su laberinto”, 1952: 116) traducido como: "Il existe une contrée où mon nom est inconnu" (1967: 157). En cuanto a los contrasentidos que se pueden considerar voluntarios, mencionemos, la traducción de “saber” por “décider” en la frase: “. . no puedo ya saber si tal o cual rasgo es una transcripción de la realidad o de las formas que desatinaron mis noches.” (“El inmortal” 1952: 15, 1967: 24), porque pensamos que el matiz entre "saber" y "decidir” no pudo escapar a Caillois, por lo cual se trata de una elección que inscribe un sentido otro en el texto.

Una segunda categoría es la de lo que podemos llamar libertades o desvíos, que pertenecen también a varios tipos distintos y suelen ser voluntarios; generalmente responden al objetivo de adaptar al gusto francés, o a lo que el traductor considera el gusto francés, es decir a la alta literatura francesa; en el caso de Caillois, se ha señalado el fenómeno particularmente en los títulos, pero a esta categoría pertenecerían también las modificaciones de la estructura de las frases y de la puntuación, así como las omisiones (fenómenos frecuentes en sus traducciones). Aunque no se puede hablar de una coherencia absoluta de los casos pertenecientes a esta categoría, en general responden a un parti pris del traductor acerca de la relación entre las lenguas literarias concernidas por la traducción, en varios niveles - puntuación, estructura de las frases, ritmo, registro, vocabulario. Notemos que Caillois exagera a menudo el gesto de adaptación a la

24 María Moliner define el contrasentido como una "interpretación contraria al sentido natural de las palabras o expresiones”, "deducción opuesta a la que es natural dados los antecedentes"; “acción, actitud, comportamiento en el que falta la correspondencia lógica” (753). Mi elección del término se debe a esta idea de la ruptura de un vínculo lógico. 
tradición literaria francesa, por ignorancia de la hispanoamericana, como hemos señalado; pero es evidente que frecuentemente en sus traducciones no ha podido discriminar lo que pertenece a la lengua y lo que pertenece al escritor (como sugiere Borges en "Las versiones homéricas”, 1932: 142). Por tanto, en esta categoría ubicamos también las traducciones que no dan cuenta de los giros, vocabulario y expresiones típicamente borgeanos del período.

El desvío más frecuente de Caillois consiste en modificar la puntuación; recurrentes son el reemplazo de comas por puntos, y de punto y coma por punto, prácticamente sistemáticos; encontramos numerosos casos de reemplazo de punto y como por coma o por punto; numerosos son los reemplazos de la conjunción “y” por punto y coma, por punto, por dos puntos, o por el relativo “où"; también frecuentes son los cambios de coma por dos puntos o por punto y coma, y los puntos por dos puntos. De un modo general, podemos afirmar que las modificaciones de puntuación responden a la intención de fragmentar el texto, y de crear un vínculo entre diferentes partes de frases o entre frases; esta fragmentación tiene como efecto alterar radicalmente el ritmo del relato, $\mathrm{y}$ borronear ciertas ambivalencias del texto borgeano; otro efecto es modificar la estructura, simplificando el texto, como por ejemplo en la primera frase de "La escritura del Dios”: "La cárcel es profunda y de piedra; su forma, la de un hemisferio casi perfecto, si bien el piso (que también es de piedra) es algo menor que un círculo máximo, hecho que agrava de algún modo los sentimientos de opresión y de vastedad" (1952: 106); he aquí la traducción de Caillois: "La prison est profonde. Elle est en Pierre. Sa forme est celle d'une demi-sphère presque parfaite ; le sol, qui est aussi en pierre, l'arrête un peu avant le plus grand cercle, ce qui accentue de quelque manière les sentiments d'oppression et d'espace" (1967 :145). De este modo, la introducción del relato presenta, en español, no solamente la cárcel, sino también el sentimiento, contradictorio, que provoca en quien la habita, en un mismo movimiento; en francés, en cambio, la división de la primera parte de la frase en dos, modifica radicalmente el efecto del texto, al tiempo que la relación concesiva es escamoteada.

Tal vez los casos más extremos de modificación en la puntuación los constituyen los momentos de transformación del estilo directo en estilo indirecto (“Abenjacán el Bojarí, muerto en su laberinto”, 1952: 116-117, 1957: 157, 161), que altera radicalmente el texto; pero podemos mencionar también la introducción de un signo de interrogación en "Historia del guerrero y la cautiva", al final de una frase cuya puntuación altera también por otros medios: "Ni siquiera sé en qué tiempo ocurrió: si al promediar el siglo VI, cuando los longobardos desolaron las llanuras de Italia; si en el VIII, antes de la rendición de Ravena." (1952: 44-45), que Caillois traduce como: "Je ne sais même pas la date des faits. Faut-il les situer vers le milieu du Ve siècle, quand les 
Longobards dévastèrent les plaines italiennes, ou dans le VIIIe siècle, avant la reddition de Ravenne ?” (1967: 64) Como vemos, aquí la frase es cortada en dos, los dos puntos se vuelven un punto, se desarma el paralelismo sintáctico entre las dos partes que siguen los dos puntos, y se introduce una interrogación explícita. En otras palabras, el planteo de ignorancia del narrador y la presentación en paralelo de dos posibilidades son escamoteados por el traductor.

Una tercera categoría es la inscripción de la interpretación del traductor en el texto traducido; esta interpretación puede ser relativa a un relato, un género, un autor. Partimos de la idea que es generalmente voluntaria, aunque es evidente que algunos de sus aspectos pueden no responder a una intención enteramente deliberada. En el caso de Caillois, hemos visto la inscripción de su interpretación de la literatura de Borges en el nivel de la edición, pero esta visión se manifiesta también en el plano de la traducción, al punto de modificar la obra de Borges. Un ejemplo evidente lo constituye el reemplazo de la palabra "red” por "labyrinthe” en "Abejacén el Bojarí, muerto en su laberinto" (1952: 114, 1967: 155), en la frase: "Dunraven dijo que en el interior de la casa había muchas encrucijadas, pero que, doblando siempre a la izquierda, llegarían en poco más de una hora al centro de la red" (114). Pero podemos también reenviar a la introducción de la palabra "race" (17) para traducir "nación" en la frase: "De lejos divisé la montaña que dio nombre al Oceáno: en sus laderas crece el euforbio, que anula los venenos; en la cumbre habitan los sátiros, nación de hombres ferales y rústicos, inclinados a la lujuria” (1952: 9-10). Caillois había introducido esta palabra también en su traducción de un poema de Gabriela Mistral publicado en la Lettres françaises en 1944, "Beber”, para reemplazar la palabra “casta” (Lettres françaises 12, 10); también la podemos relacionar con las concepciones de Caillois sobre la cultura, y la polémica que mantiene con Claude Lévi-Strauss cuando este publica Race et histoire en 1952 (Felgine 321-322; Panoff). La traducción de la frase siguiente a la que ya hemos citado de "Historia del guerrero y la cautiva", presenta un ejemplo de inscripción de la interpretación del traductor en el texto: "Imaginemos (éste no es un trabajo histórico) lo primero" (1952: 45), traducido por: "Choisissons (ceci n'est pas un travail historique) la première hypothèse” (1967: 64), donde el reemplazo de "Imaginemos" por "Choisissons" y la introducción de la palabra científica "hypothèse" desplaza el texto del terreno de la literatura y la imaginación hacia el de la reflexión científica ${ }^{25}$.

25 El párrafo siguiente retoma la idea de imaginación ("Imaginemos, sub specie aeternitatis, a Droctulft, no al individuo Droctulft, que sin duda fue único e insondable...” (1952: 45)), Caillois pasa por alto el paralelismo de las dos frases, pero traduce en esta frase por "Imaginons" (1967: 64). 
La clasificación propuesta presenta dos problemas. Por un lado, no es exclusiva de Caillois, es decir que podemos encontrar estas tendencias en otros traductores, aunque muchos traductores intentan reducir ya sea los contrasentidos, las libertades o la inscripción de la propia interpretación. Si es cierto que Caillois está atento a los primeros, no podemos decir lo mismo de las otras categorías: tanto las libertades como la inscripción de la concepción del traductor en su caso son conscientes, deliberadas y están particularmente desarrolladas, en razón de sus concepción de la lengua francesa y porque se consideraba él mismo como una autoridad suficiente para cuestionar las elecciones del autor (tal como lo muestran los testimonios de Ibarra y de Cortázar, y lo confirman su escritura y su práctica de las traducciones) ${ }^{26}$. El otro problema que presenta esta categorización es que no es siempre posible diferenciar el tipo de intervención del traductor; de un modo general, podemos concluir que prácticamente todos los desvíos pueden también considerarse como modos de inscripción de la interpretación del traductor, cuando no responden a un desconocimiento del lenguaje o de sus connotaciones; lo interesante es estudiar cada caso y sus implicaciones. Como ejemplo, podemos examinar el título de uno de los relatos publicados primero en Labyrinthes y después en El Aleph, "La busca de Averroes" traducido por Caillois como "La quête d'Averroès". Como es sabido, en el cuento de Borges, Averroes intenta comprender el sentido de las palabras

26 Según Ibarra: “Tout bonnement je me demande si lui [Bénichou] et Caillois ne se souviennent pas trop de leurs années de professorat secondaire. Ils sont peut-être marqués à jamais par la version latine. Ils savent trop que Amat janua limen ne doit pas être traduit par la porte aime le seuil, parce que l'élève qui traduit ainsi ne fait pas comprendre qu'il a compris, montre plutôt qu'il n'a pas compris (il s'agit d'une porte qui ne quitte plus le seuil, que personne n'ouvre plus, celle d'une vieille courtisane désaffectée)." ("Me pregunto simplemente si él [Bénichou] y Caillois no recuerdan demasiado sus años de profesores de la secundaria. Están marcados para siempre por la versión latina. Saben demasiado bien que Amat janua limen no debe ser traducido por la puerta ama al umbral, porque el alumno que traduce de este modo no da a entender que ha entendido, sino que muestra más bien que no ha comprendido (se trata de una puerta que no abandona el umbral, que nadie abre ya, la de una vieja cortesana olvidada”) (151-152)). Y Cortázar, en carta a Jean Barnabé, del 8 de mayo de 1957: "Creo haberle dicho en mi carta anterior - anterior a mi partida a la India - que le llevé Bestiaire a Caillois. Me lo devolvió diciéndome que las traducciones le parecían 'demasiado apegadas al original' (sic.). Cuando le pedí que me aclarara lo que quería decir sostuvo que usted había sido 'demasiado fiel' en algunas cosas, alejándose del francés para mantenerse más cerca del giro español, del ritmo de la frase, etc. Creo que fue en ese momento que comprendí por fin por qué las traducciones al francés me parecen casi siempre demasiado alejadas del original; evidentemente la gente como Caillois considera que el autor no interesa gran cosa: lo único que cuenta es salvar a toda costa el GRRRAANNN estilo francés, la manera francesa de decir las cosas. . . aun a riesgo de cualquier traición” (125). 
“tragedia” y “comedia” en Aristóteles, viniendo de una cultura que no conoce el teatro. Para Néstor Ibarra, la traducción del título que propone Caillois es un error: "Caillois préfère La quête d'Averroès, je ne sais pourquoi. Il s'agit d'une recherche littéraire...On ne fait pas de quêtes à la Nationale que je sache ?” $(441)^{27}$. La elección de Caillois, sin embargo, puede explicarse por dos razones; por un lado, el uso poco común de la palabra "busca” (pareciera que para Borges "búsqueda" era una palabra vulgar), que puede haber percibido como un término literario e incluso antiguo; por otro lado, la noción de "quête" introduce una dimensión metafísica que corresponde perfectamente a su lectura de Borges (e introduce también una connotación espiritual); notemos que la palabra se traduce en español por "búsqueda”, pero en esta traducción se pierde la dimensión espiritual y metafísica, razón por la cual tal vez Caillois considera que es un equivalente de "busca". Podemos entonces preguntarnos si se trata de una libertad tomada por razones lingüísticas o de una introducción de la interpretación del traductor, y responder que ambas se combinan en este caso ${ }^{28}$.

A la intención y voluntad de inscribir su lectura de la obra de Borges, se suma otra cuestión, que encontramos también en sus traducciones y ediciones de Julio Cortázar, pero que ya se manifiesta en los años 1940, en el momento en que Borges, Bioy y Silvina Ocampo publican la Antología de la literatura fantástica $^{29}$ : Caillois suele considerar el género fantástico a partir de su vertiente europea, y su concepción no corresponde a la naciente práctica del género en América Latina, por lo cual sus traducciones atenúan ciertos efectos, e introducen cierto grado de explicación en un universo fantástico que suele rechazar toda explicitación ${ }^{30}$. En sus traducciones y ediciones va a inscribir su propia

27 "Caillois prefiere La quête d'Averroès, no sé por qué. Se trata de una investigación literaria... No se hacen « quêtes » en la nacional que yo sepa?”.

28 Un fenómeno similar se observa en la traducción del título "La casa de Asterión”, que Caillois traduce pour "La demeure d'Astérion", que por falta de espacio no podemos analizar aquí, pero señalemos que "demeure" es una palabra que no reenvía necesariamente al mundo humano, por lo cual se borra así parte del proceso de humanización del Minotauro, y disminuye el suspenso del texto.

29 En una carta del 7 de abril de 1941, Roger Caillois le escribe a Victoria Ocampo acerca de la Antología de la literatura fantástica, criticando las elecciones hechas por los compiladores, y el hecho de haber incluido un texto de Borges (Felgine 114-115).

30 La misma carta a Jean Barnabé del 8 de mayo de 1957, donde Julio Cortázar le cuenta su entrevista con Caillois y su discusión a propósito del cuento "La noche boca arriba", permite comprender su concepción: "Una semana más tarde Caillois me dijo que había elegido un cuento para incluirlo en una antología de contes d'épouvante (!) que va a editar Gallimard. Eligió "La noche boca arriba", que tradujo enseguida un señor Durand. Para darle una idea de la mentalidad de Caillois, le regalo esta pequeña anécdota. "El peligro de su cuento" (es él quien habla) "está en que el lector francés pueda pensar que se trata simplemente de una 
concepción, de modo en parte deliberado, modificando el significado de los textos, o intentando modificarlo; no se trata, como se ha pretendido a menudo, de una falta de comprensión de parte de Caillois de la literatura latinoamericana, sino de una concepción otra, que entra en competencia con la de Borges, Bioy, Cortázar, y con algunos principios del género hispanoamericano. Desde su lugar de traductor y editor, inscribe su propia concepción, usando la práctica de la traducción, así como la de la antología y del ensayo, para enfrentar las teorías a las que no adhiere, como podemos verlo en su Anthologie de la littérature fantastique (1966). Caillois no ganó esta batalla (por suerte), la literatura fantástica latinoamericana se impuso con sus peculiaridades, pero en los años 1950, 1960 el enfrentamiento de estas concepciones no permite aún saber cuál de estas estéticas se impondrá, y en la batalla librada por Caillois la traducción juega un papel preponderante $\mathrm{e}^{31}$.

Esta competencia de tendencias estéticas se manifiesta en particular en la dificultad que manifiesta Caillois para dejar las interpretaciones libradas al lector, principio que responde a una concepción pedagógica de la literatura y del lenguaje, destinada a construir y confirmar el lugar privilegiado que ocupa el escritor (cercana a la de Victoria Ocampo); por ello, sus traducciones y ediciones muestran una tendencia a explicitar, a resolver las ambivalencias (línea continuada en relación con lo fantástico por Todorov 1970). Cuando se trabaja con la lengua, estas concepciones se manifiestan de modo voluntario, pero se inscriben también de modo involuntario en numerosas elecciones y decisiones de traducción. En este sentido hemos señalado la fuerte tendencia a la explicación, explicitación e interpretación en las traducciones de Caillois, mediante, como vimos, agregados, supresiones, modificaciones de la puntuación, introducción de bastardilla, y desvíos en el nivel semántico.

Tal vez haya sido Ibarra quien mejor expresó el problema que plantean las traducciones de Borges hechas por Caillois (y otros traductores franceses): “Ils veulent, eux, traducteurs de Borges, laisser trace qu'ils l'ont bien interprété; mais voilà, en l'interprétant, ils privent le lecteur de la joie de l'inter-

alucinación del hombre a quien ha operado... ¿No le parece que convendría agregar una frase final, por ejemplo que a la mañana siguiente los enfermeros encontraron muerto al enfermo, y al mirarlos con atención se dieron cuenta de que tenía una herida en el pecho y que le faltaba el corazón?” (!!!) Yo me quedé mirándolo como si me estuviera tomando el pelo, pero hablaba con toda seriedad" (126). Notemos que, si Cortázar reproduce fielmente las palabras de Caillois, este dice "el lector francés", lo que significa que la ambigüedad del final del texto le parece un problema solamente para este lectorado.

31 Es evidente, por otra parte, que la publicación de la Introduction à la littérature fantastique de Todorov en 1970 va a modificar la historia literaria. Ver Louis, "Del rol de la delimitación". 
préter”(152) ${ }^{32}$. Y agrega, subrayando el papel de intérprete que se otorga de este modo el traductor: "La littéralité, notamment, inspire à ses traducteurs de la méfiance, sinon de l'horreur. Ils voient partout des "faux amis"; les "faux amis" les détournent des vrais. Et Nous aboutissons à ce paradoxe qu'en lisant Borges en espagnol, Nous le sentons s'adresser à des lecteurs beaucoup plus fins, plus lettrés, plus "artistes" qu'en le lisant dans ses traductions françaises !" $(152-153)^{33}$. La escritura de Borges abre, en efecto, un espacio al lector para que interprete, rechazando deliberadamente toda explicitación y a menudo toda explicación - un procedimiento particularmente importante en el género fantástico. Es la razón por la cual Enrique Pezzoni consideraba su literatura como antipedagógica, porque demanda un lector activo, dispuesto a socavar las bases del pensamiento occidental (45). Traducir da la posibilidad al traductor de llenar ese espacio de la escritura, de inscribir un "rastro" en ella, marcándola con la propia concepción, en este caso: explicitando, simplificando, explicando aquello deliberadamente dejado en suspenso por el autor. Y tal vez el modo en que se ocupa ese espacio es parte del éxito de una traducción en un momento determinado y en una cultura específica, porque inscribe la imaginación del traductor, y toda imaginación es social.

\section{Traductores, agentes, autores}

Introducir un autor extranjero en una cultura (lo que se suele llamar transferencia cultural) es necesariamente una operación cargada de sentido, y de consecuencias, puesto que toda interpretación de una obra lleva a un montaje editorial particular. El rasgo más llamativo del caso de Borges es el hecho que la obra haya sido presentada y organizada a partir de un tema, que funciona a la vez como un articulador como un unificador, y que es propuesto simultáneamente como universal y como específico a la cultura occidental: el

32 "Ellos, los traductores de Borges, quieren dejar una huella que muestre que lo han interpretado bien; pero al interpretarlo, privan al lector de la alegría de hacerlo ellos”. También según Ibarra: "Labyrinthes est une sorte de jugement porté sur Borges, une définition de Borges par Caillois" (92) (“Labyrinthe es una suerte de juicio sobre Borges, una definición de Borges por Caillois").

33 "La literalidad, en particular, inspira desconfianza a sus traductores, y a veces horror. Ven en todas partes 'falsos amigos'; los 'falsos amigos' los alejan de los verdaderos. Y llegamos asî a esa paradoja, que cuando leemos a Borges en español, sentimos que se dirige a lectores mucho más finos, más letrados, más ‘artistas', ique al leer sus traducciones francesas!”. 
laberinto, inscripto en una red de motivos (el tiempo, la biblioteca, el tigre). Edición y traducción son puestas al servicio de este objetivo, aunque en el caso de las traducciones otros factores también contribuyen a otorgarles una identidad.

Contrariamente a lo que se suele creer, y a lo que se ha sostenido a menudo, Roger Caillois no inventó la idea de difundir la obra de Borges a partir de un tema; pero al poner en evidencia el del laberinto, fue uno de los agentes de su difusión, quizás el principal (pero otros factores quedan por estudiar). Si hizo posible la articulación de la literatura de Borges a la cultura francesa, la asociación entre Borges y una serie de temas universales, extranjero a su contexto de producción había nacido en Buenos Aires, en el comienzo de los años 1940, en el momento de la primera recepción de sus cuentos en su propio medio cultural. Esta lectura se explicitó durante el discreto escándalo provocado por el Premio Nacional de Literatura en 1942, que llevó a los enemigos y a los defensores de su estética a expresar sus posiciones (Louis, Borges 95-104); lecturas que probablemente influyeron en la presentación de Ibarra para las “Assyriennes”. Todos acontecimientos que se producen mientras Caillois está todavía en Buenos Aires.

La creación de Labyrinthes por Caillois extendió el automatismo que consiste en asociar a Borges al laberinto más allá del ámbito de la literatura; la lista es larga de todo aquello que aparece como laberíntico y borgeano -el libro, la biblioteca, los barrios de Buenos Aires, el tiempo, el jardín; la cultura es un laberinto, como el universo y la paradoja de Zenón; la web y el internet-. Uno de los problemas que debe enfrentar la interpretación temática es cómo lograr hablar de temas o ideas en literatura sin reducir su especificidad, es decir, sin hacer de la literatura un simple sistema de traducción. Aquí, nos encontramos con el caso opuesto: la obra de Borges se impuso sobre el tema del laberinto, y se lo apropió ${ }^{34}$. El tema no traduce (ni reduce) la obra de Borges: la obra de Borges encarna el tema, y se impone en toda ocurrencia de laberinto, expandiéndose de este modo más allá de su textualidad.

34 En otras palabras, se trata del movimiento opuesto al que se produjo en el comienzo, lanzado por Caillois, que había sido definido del siguiente modo por Ibarra: "Un peu partout dans son œuvre, Borges imagine, dénonce, divers labyrinthes; Caillois les ramasse tous en un seul et y enferme Borges" (93) ("En varios momentos en su obra, Borges imagina, denuncia, diferentes laberintos; Caillois los junta todos en uno solo y encierra adentro a Borges”). 


\section{Bibliografía}

Bastide, Roger. "Sous 'La Croix du Sud': l'Amérique latine dans le miroir de sa littérature”. Annales a 13, no. 1, 1958, pp. 30-46.

Borges, Jorge Luis. Euvres Complètes. Tome 1. Gallimard/NRF/La Pléiade, 1993. Édition établie, présentée et annotée par Jean-Pierre Bernès. Tome 2. Gallimard/NRF/La Pléiade, 1999.

---. L'Aleph. Trad. Roger Caillois y René L.-F. Durand. Gallimard, colección “Du monde entier”, 1967.

---. Essai sur les anciennes littératures germaniques (en collaboration avec María Esther Vázquez). Trad. Michel Maxence. Christian Bourgois, 1966.

--.. Discussion. Gallimard, collection “La Croix du Sud”, 1966.

--.. Manuel de zoologie fantastique. (en collaboration avec Margarita Guerrero). Trad. Roger Caillois. Lettres Nouvelles, 1965.

-.-. L'Auteur et autres textes. Trad. Roger Caillois. Gallimard, colección “La Croix du Sud”, 1965.

--.. La Bibliothèque de Babel. Trad. Nestor Ibarra. R. Gid, 1963.

--.. Labyrinths. Selected Stories and Other Writings. Trad. James E. Irby et al. Ed. Donald

A. Yates y James E. Irby. Prefacio de André Maurois. New Directions, 1961.

---. Labyrinthe. Erzählungen. Trad. Karl August Horst. Carl Hanser Verlag, 1961.

---. Histoire de l'infamie. Histoire de l'éternité. Trad. Roger Caillois y Laure Guille (con la ayuda de Julio Cortázar). Editions du Rocher, 1958; Union générale des éditeurs, colección “Le Monde" en 10/18, 1964.

---. Enquêtes 1937-1952. Trad. Paul y Sylvia Bénichou. Gallimard, colección “La Croix du Sud", 1957.

--.. “L'immortel”. Trad. Roger Caillois. La Nouvelle Revue Française, 1/09/1953, a. 1, no. 9, pp. 422-439.

--.. "Nota sobre (hacia) Bernard Shaw". Otras inquisiciones. Sur, 1952, pp. 193-196.

---. “El hombre en el umbral”. La Nación 2e, 20/04/1952: 1, 2da sección, ilustración de Alejandro Sirio. El Aleph. Losada, 1952, pp. 131-137.

--.. “Abenjacán el Bojarí, muerto en su laberinto”. Sur, no. 202, 08/1951, pp. 1-8./El Aleph. Losada, 1952, pp. 113-123.

---. “La espera”. La Nación 27/08/1950: 1, 2da. Sección, ilustración de Alejandro Sirio. El Aleph. Losada, 1952, pp. 123-130.

---. Fictions. Trad. Paul Verdevoye y Néstor Ibarra. Prólogo de Néstor Ibarra. Gallimard, colección "La Croix du Sud”, 1951.

-.-. "Histoire du guerrier et de la captive". Trad. Roger Caillois. Cahiers de la Pléiade, Otoño de 1949, pp. 159-164.

---. “La casa de Asterión”. Los Anales de Buenos Aires a. 2, no. 15-16, 05/1947, pp. 47-49; El Aleph. Losada, 1949, pp. 69-72.

---. "Los inmortales”. Anales de Buenos Aires a.2, no.12, 02/1947, pp. 29-39, ilustración de Amanda Molina Vedia. Bajo el título de "El inmortal”, El Aleph. Losada, 1949, pp. 7-28.

---. "Fictions". Trad. Paul Verdevoye. La Licorne. no. 1, primavera de 1947, pp. 13-26.

--.. "Les ruines circulaires". Trad. Paul Verdevoye. Confluences (nueva serie), año 6 ${ }^{\mathrm{e}}$, no. 11, abril de 1946, pp. 131-135. 
--.. “Assyriennes”. Trad. Néstor Ibarra. Lettres françaises, no. 14, Buenos Aires, 01/10/1944, pp. 9-26.

--.. "Historia de los dos reyes y los dos laberintos". El Hogar, vol. 35, no. 1548, 16/06/1939, p. 25 (bajo el título de "Una leyenda arábiga (Historia de los dos reyes y los dos laberintos, como nota de Burton)"; bajo el título de "Historia de los dos reyes y los dos laberintos", en Los Anales de Buenos Aires vol. 1, no. 5, mayo de 1946, p. 51, sección "Museo", compuesta en colaboración con Bioy Casares y publicada bajo el seudónimo de B. Suárez Lynch. El Aleph, Losada, 1952, p. 51.

---. “L’approche du caché”. Trad. Néstor Ibarra. Mesures, 1939, pp. 115-122.

--. "Laberintos". Obra a.1, no. 3, 01/1936, pp. 38-39. Bajo el seudónimo de Daniel Haslam.

--.. “Nota sobre la 4ta dimensión”. Obra 1, no. 5, 04/1936, pp. 38-39. Bajo el seudónimo de Daniel Haslam. Publicado antes en la Revista Multicolor de los Sábados. Crítica 1, no. 51, 28/07/1934, p. 4.

--. “Un infinito problema. El mentiroso. El cocodrilo. El puente. El adivinador”. Obra 1, no. 6, 05/1936, p. 38. Bajo el seudónimo de Daniel Haslam. (Habían ya sido publicados en la Revista Multicolor de los Sábados. Crítica, bajo el título de "Dos antiguos problemas"1, no. $40,12 / 05 / 1934$, p. 5.)

--.. "Paul Groussac". La Revue Argentine, dic.-enero 1936, p. 33-36.

--.. “Los laberintos policiales y Chesterton”. Sur, no. 10, mayo 1935, pp. 92-94.

---. "Leyes de la narración policial”. Hoy Argentina, vol. 1, no. 2, abril 1933, pp. 48-49.

---. “Las versiones homéricas”. Discusión. Manuel Gleizer, 1932, pp. 13-150.

Caillois, Roger. Approches de la poésie. Gallimard, 1978.

--.. Anthologie du fantastique. Gallimard/NRF, 1966.

--.. "Les thèmes fondamentaux de Jorge Luis Borges". Jorge Luis Borges. Ed. Dominique de Roux y Jean de Milleret. L'Herne, 1964, p. 211-217.

--.. “Poètes d’Amérique. Note”. Lettres françaises, no. 12, 01/04/1944, pp. 7-8.

--.. “Manifeste pour une littérature édifiante”. Lettres Françaises, no. 13, 1/07/1944, pp. 1-5.

---. Les impostures de la poésie. Sur, 1944.

Caillois, Roger y Paulhan, Jean. Correspondance. (1934-1967). Cahiers Jean Paulhan, no. 6. Presentación y anotaciones de Odile Felgine y de Claude-Pierre Perez, con la colaboración de Jacqueline Paulhan, prefacio de Laurent Jenny. Gallimard, 1991.

Caillois, Roger. y Victoria Ocampo Correspondance. Stock, 1997.

Cortázar, Julio. Cartas. 5 vol. Eds. Aurora Bernárdez y Carles Álvarez Garriga. Alfaguara, 2012. Dulou, Jérôme. “Julio Cortázar et Roger Caillois: du rêve au fantastique”. Tesis de doctorado Nouveau Régime. Paris IV, 30/05/2018.

Felgine, Odile. Roger Caillois (biographie). Stock, 1994.

Ibarra, Néstor. Borges et Borges. L'Herne/Glose, 1969.

Louis, Annick. "La traduction dans la revue Lettres françaises (1941-1947) de Roger Caillois". Scènes de la traduction France/Argentine. Ed. Gersende Camenen. Editions Rue d’Ulm, 2019. (en prensa)

---. “Étoiles d'un ciel étranger. Roger Caillois et l'Amérique Latine”. Littérature. Roger Caillois, no. 170 , junio 2013 , pp. $71-81$.

---. "Del rol de la delimitación del corpus en la teoría literaria. A propósito de la Introducción a la literatura fantástica de Tzvetan Todorov y de la crítica literaria hispanoamericana". Badebec, vol. 2, no. 3, septiembre 2012, pp. 118-142.

---. Borges ante el fascismo. Peter Lang, 2007.

Mistral, Gabriela. Poèmes. Trad. Roger Caillois. Gallimard, 1946. 
Moliner, Maria. Diccionario de uso del español. Gredos, 1986.

Molloy, Sylvia. La diffusion de la littérature en France au xx ${ }^{e}$ siècle. PUF, 1972.

Panoff, Michel. Les frères ennemis. Roger Caillois et Claude Lévi-Strauss. Editions Payot et Rivages, 1993.

Pezzoni, Enrique. Enrique Pezzoni lector de Borges. Lecciones de literatura 1984-1988. Edición y prefacio de Annick Louis. Sudamericana, 1999.

Río de la Plata, números 13-14, 1992.

Schaeffer, Jean-Marie. "Thématique". Nouveau Dictionnaire encyclopédique des sciences $d u$ langage. Ed. Oswald Ducrot y Jean-Marie Schaeffer. Seuil, 1995, pp. 530-532.

Taminiaux, Pierre. "Roger Caillois et l'expérience de la traduction". Revue des lettres et des traductions, no. 9, 2003, pp. 39-51.

Todorov, Tzvetan. Introduction à la littérature fantastique. Seuil, 1970. 